\title{
Identification and analysis of immune-related transcriptome in Asian seabass Lates calcarifer
}

\author{
Jun Hong Xia and Gen Hua Yue*
}

\begin{abstract}
Background: Fish diseases caused by pathogens are limiting their production and trade, affecting the economy generated by aquaculture. Innate immunity system is the first line of host defense in opposing pathogenic organisms or any other foreign material. For identification of immune-related genes in Asian seabass Lates calcarifer, an important marine foodfish species, we injected bacterial lipopolysaccharide (LPS), a commonly used elicitor of innate immune responses to eight individuals at the age of 35 days post-hatch and applied the suppression subtractive hybridization (SSH) technique to selectively amplify spleen cDNA of differentially expressed genes.

Results: Sequencing and bioinformatic analysis of 3351 ESTs from two SSH libraries yielded 1692 unique transcripts. Of which, 618 transcripts were unknown/novel genes and the remaining 1074 were similar to 743 known genes and 105 unannotated mRNA sequences available in public databases. A total of 161 transcripts were classified to the category "response to stimulus" and 115 to "immune system process". We identified 25 significantly up-regulated genes (including 2 unknown transcripts) and 4 down-regulated genes associated with immune-related processes upon challenge with LPS. Quantitative real-time PCR confirmed the differential expression of these genes after LPS challenge.

Conclusions: The present study identified 1692 unique transcripts upon LPS challenge for the first time in Asian seabass by using SSH, sequencing and bioinformatic analysis. Some of the identified transcripts are vertebrate homologues and others are hitherto unreported putative defence proteins. The obtained immune-related genes may allow for a better understanding of immunity in Asian seabass, carrying out detailed functional analysis of these genes and developing strategies for efficient immune protection against infections in Asian seabass.
\end{abstract}

\section{Background}

Fish diseases caused by viruses, bacteria and parasites are recognized as a significant constraint on aquaculture production and trade hence affecting the economy seriously $[1,2]$. A global estimate of disease losses in aquaculture surpassed US\$ 9 billion per year, which is about $15 \%$ of the value of world farmed fish and shellfish production [3]. Successful defence against pathogenic infection is dependent on the ability to detect the presence of the invading pathogen [4-6]. Teleost fish possess the elements of both the innate defence system and the acquired specific immune system [7]. However, the adaptive immune response in fish is less developed than that in higher vertebrates [5]. Therefore, innate immune system is quite important in fish and believed to be the first line

* Correspondence: genhua@tll.org.sg

1 Molecular Population Genetics Group, Temasek Life Sciences Laboratory, National University of Singapore, 117604 Republic of Singapore Full list of author information is available at the end of the article of host defence in opposing pathogenic organisms or any other foreign material $[4,7]$. In aquaculture, the basic data on fish-pathogen interactions have been effectively applied for large scale vaccination to aid in the generation of robust and long-lasting immune responses [8,9]. However, the development of an effective vaccine is a complex process. The prerequisites for developing vaccines are the understanding of the basic epidemiology of diseases and the immune system of the target species and identifying the genes and pathways involved in transcript response of a fish upon infection [10,11].

Expressed sequence tags (ESTs) generated by cDNA cloning have proven to be a powerful and rapid tool for identifying genes [12-14]. ESTs also form the basis for subsequent microarray design, SNP detection and the placement of novel markers on genetic linkage maps [13,15-18]. Currently ESTs are available from a large number of fish species, such as European seabass [19], halibut [13], cod [20], trout [16], salmon [15], European 
and Japanese flounders [21] and catfish [17] which enabled the identification of immune-related genes in these species. However, screening for immune-related genes in EST databases using bioinformatic tools allows identification of only those genes that share sequence similarities with known immune-related proteins from other organisms [22], but misses novel genes related to immune responses. Suppression subtractive hybridization (SSH) [23] can be applied to identify differentially expressed genes in different tissues or conditions and thus is also a highly effective method for identifying novel genes related to important biological processes. This technique has been proven to be a suitable tool for identification of novel immune-related genes in a variety of teleost fish species, including flounder [21,24,25], rainbow trout [26], salmon [27-29], grouper [30], croaker [31], cod [32], sea bream [14,33], turbot [34], dogfish [35] and European seabass [36].

The Asian seabass Lates calcarifer distributed in the tropical and sub-tropical areas of Asia is an important marine foodfish species in Southeast Asia and Australia. This species has been cultured for more than 20 years in brackish-water ponds and in recent years in floating cages. The global annual production of Asian seabass was currently 400,000 metric tons according to FAO statistics $[37,38]$. In the past few years, we conducted a breeding program for Asian seabass [37] and developed a number of genomic tools such as microsatellites [39], SNPs in genes [40], linkage maps [37], BAC and cDNA libraries $[40,41]$ to facilitate the selective breeding program. Massive mortalities caused by bacterial or viral infections in intensive aquaculture production have caused serious economic losses in Asian seabass aquaculture. Some kinds of bacteria, such as Cytophaga johnsoniae and Streptococcus iniae have currently been isolated from sick seabass in Singapore [42], Thailand [43] and Australia $[44,45]$. In order to shield the aquaculture loss by pathogenic diseases, Asian seabass aquaculture urgently requires effective disease prevention strategies. Although some studies had shown that Asian seabass exhibited strong immune responses against bacteria based on the antibody activities in sera [46], little information on host-pathogen interaction during infection with pathogenic microorganisms is available for this species.

Immune response can be experimentally stimulated by bacterial lipopolysaccharides (LPS) [47-49]. cDNA libraries of liver, kidney and spleen have been proven to be an excellent source of genetic information concerning immune function in fish [13]. The aim of this study was to identify and analyze immune-response genes in Asian seabass by challenging individuals with LPS, the SSH technology and bioinformatic tools.

\section{Results}

SSH efficiency

The efficiency of subtraction can be estimated with PCR analysis by comparing the abundance of housekeeping genes and differentially expressed genes before and after subtraction (Clontech manual). In this experiment, an immune-related gene (the immunoglobulin heavy constant mu: IGHM) and a house-keeping gene (Đ-actin) were used to examine the efficiency of subtraction. Quantitative real-time PCR analysis of IGHM and Đactin revealed that SSH efficiency was 3.4 fold for the forward subtractive library and 4.7 fold for the reverse subtractive library.

\section{Generation of subtractive cDNA libraries and assembly of ESTs}

Two subtractive cDNA libraries, a forward subtractive library (genes expected to be up-regulated in response to immune challenge in this library) and a reverse subtractive library (genes expected to be down-regulated in response to immune challenge) were constructed using subtractive cDNA from spleen of Asian seabass sampled at 24 hour post challenge with LPS and control samples. A total of 1527 and 1824 randomly picked clones for the forward subtractive library and the reverse subtractive library, respectively, were sequenced. After trimming of end and vector sequences and eliminating sequences with low quality and/or shorter than 100 bases, a total of 2887 high quality sequences were obtained. Among the 2887 high quality sequences 1168 were derived from the forward subtractive library whereas 1719 from the reverse subtractive library (Table 1).

After assembly and clustering, 1692 unique transcripts consisting of 1207 singletons and 485 contigs (Table 1) were obtained. Among the 485 contigs, 290 (60.2\%) contained 2 ESTs, 130 (26.8\%) had 3-4 ESTs and 63 (13.0\%) consisted of 5 or more sequences. The largest contig was formed by 97 ESTs.

\section{Annotation of ESTs}

Blast searches against known sequences in public databases using the programs BLASTx and BLASTn revealed that 1074 unique transcripts were similar to 743 known genes and 105 unannotated mRNA sequences with high confidence $\left(\mathrm{E}\right.$ value $\left.<10^{-4}\right)$ in the database. The remaining 618 unique transcripts were potentially novel sequences or UTRs of known genes. Three hundred and thirty-one of these known genes and unannotated mRNA sequences were represented by multiple sequences (see Additional file 1). Among the known genes and mRNA sequences represented by EST clones, 542 were found in the reverse subtractive library and 467 were found in the forward subtractive library, respectively. Of which, 161 were present in both libraries. The percentage ( 9\%) of 
Table 1: EST sequences and assembly statistics for two suppression subtractive hybridization libraries constructed from spleen cDNA of Asian seabass

\begin{tabular}{llll}
\hline & $\begin{array}{l}\text { Forward subtractive } \\
\text { library }\end{array}$ & Reverse subtractive library & Sequences combined \\
& & & \\
\hline Total number of sequences & 1527 & 1824 & 3351 \\
Clean sequences $(>100 \mathrm{bp})$ & 1168 & 1719 & 2887 \\
Low quality sequences & 359 & 105 & 464 \\
Total number of unique sequences & 761 & 1093 & 1692 \\
Singlets & 588 & 797 & 1207 \\
Contigs & 173 & 296 & 485 \\
$\quad 118$ & 196 & 292 \\
$\quad 3-4$ ESTs & 41 & 72 & 130 \\
$\quad 14$ ESTs & 14 & 28 & 63 \\
SNP-contained contigs & -- & -- & 303 \\
Microsatellite -contained unique sequences ( $\geq 8$ repeats) & -- & -- & 20 \\
\hline
\end{tabular}

unique transcripts presented both in reverse and forward subtractive libraries was slightly higher than that in some previous studies (3-5.95\%), such as on grouper Epinephelus coioides [50]. This might be related to the nature of $\mathrm{SSH}$ technique used in this study. Although differentially expressed genes were enriched significantly with the approach, some of the unwanted genes might not have been eliminated completely in the libraries. When more clones of the SSH libraries were sequenced, as in our study, more rare transcripts would be found in both of the forward and reverse libraries. This should increase the percentage of unique transcripts that are present both in reverse and forward subtractive libraries.

The globin gene family was among the predominant EST sequence clusters in both libraries. Of the 2887 EST sequences, $13.8 \%$ (397) matched the globin family (hbaa1, ba1, hbb, Hba-x), 5.7\% (165) were ribosomal proteins (12 S, $16 \mathrm{~S}, 18 \mathrm{~S}, 40 \mathrm{~S}$ and $60 \mathrm{~s}), 1.6 \%$ (47) were initiation factors and $1.2 \%$ (34) belonged to elongation factors (Additional file 1). These results probably reflect that the fish were in an active growth stage. Interestingly, the expression of the globin gene family $(\mathrm{p}<0.0001)$ and elongation factors $(p=0.0023)$ were significantly differentiated between two libraries, indicating some globin proteins (up-regulated upon LPS challenge) and elongation factors (down-regulated upon LPS challenge) might play important roles in host defence.

The complete results of BLAST searches of the Asian seabass ESTs from the forward subtractive and reverse subtractive libraries are summarized in Additional file 1.

\section{Functional classification}

Available bioinformatic tools, such as the Gene Ontology (GO) GO Slimmer and Kyoto Encyclopedia of Genes and Genomes (KEGG) provide useful information to analyze the functional profile of annotated genes [51]. A total of 743 annotated genes were used in functional classification (Additional file 1). According to GO Slimmer results, genes encoding for proteins associated with cellular process, metabolic process and biology regulation in category of biological processes (Additional file 2) were the three largest annotated subcategories. The second largest group was genes encoding products related to regulation of biological process, response to stimulus and developmental process in both of the forward subtractive library and the reverse subtractive library. The remaining genes encoded products were involved in many other diverse biological processes. With respect to cellular components (Additional file 3), we observed that a large proportion of sequences were classified into cell, cell part and organelle followed by organelle part, macromolecular complex, extracellular region and membrane-enclosed lumen in the forward and the reverse subtractive libraries. As expected, a remarkably high proportion of annotated sequences were categorized as binding and catalytic activity followed by transcription regulator activity and transporter activity in both of the libraries (Additional file 4). Analysis of GO categories showed that the functional distribution of the genes of the two libraries in the three categories was similar $(P>0.05)$. The detailed information of functional classification is shown in Additional file 5 and 6.

KO (KEGG Orthology) is a pathway-based classification of orthologous gene groups. Four hundred and sixty seven of the 1692 unique transcripts with $\mathrm{KO}$ assignments were composed of 402 unique genes. Of which, 257 unique genes belonged to 160 KEGG pathways. Interestingly, 52 annotated genes were found in 10 immune-related pathways, including complement and coagulation cascades (13 hits), chemokine signaling path- 
way (12 hits), antigen processing and presentation (10 hits), Toll-like receptor signaling pathway (9 hits), leukocyte transendothelial migration (8 hits), $\mathrm{T}$ cell receptor signaling pathway (7 hits), hematopoietic cell lineage (6 hits), B cell receptor signaling pathway (5 hits), natural killer cell mediated cytotoxicity (4 hits) and Fc epsilon RI signaling pathway (3 hits). Most of the annotated genes were associated with cellular process (213 hits) and diseases (171 hits) and metabolism (167 hits), followed by environmental (79 hits) and genetic (70 hits) information processing. Our data suggest that several important immune processes were likely to be affected by the LPS challenge.

\section{Immune-related genes and differentially expressed genes in subtractive libraries}

Genes in the GO subcategories 'response to stimulus' and 'immune system process' are likely to be involved in the interaction of bacteria with its host. We identified a total of 161 genes (78 in the forward subtractive library and 111 in the reverse subtractive library) with response to the LPS challenge, whereas only 28 genes were shared between two libraries. These genes were mainly associated with response to stress (81), response to chemical stimulus (80), response to external stimulus (48), cellular response to stimulus (40), regulation of response to stimulus (35) and immune response (36). Most of the responsive genes were under represented in the library with only one copy in each library. Although the percentage of unique genes responding to stimulus contained in both libraries was not significant, the actual number of the EST clones representing these genes (396 in the forward subtractive library and 384 in the reverse subtractive library) was quite different between two libraries $(P<$ 0.0001). In addition, $13.3 \%$ of the EST clones (383) matched the genes in immune system process (115 unique genes) based on GO term and KAAS data. The EST clones of immune genes were found statistically different between two libraries $(P<0.0001)$. Majority of the immune and stress-related EST sequences identified in this study (Additional file 5 and 6) were reported for the first time in the Asian seabass.

Based on the number of homologous ESTs in the two libraries, Fisher's exact test found a significant increase in abundance for a total of 25 genes (including 2 unknown genes) and a significant decrease in abundance for 4 genes upon challenge with LPS, suggesting a strong transcriptional regulation upon LPS challenge (Table 2). Homologues of some immune-related genes such as LY6 $D$ and EEF2L were found exclusively in one library, and some others such as C1QL4L and HMOX1 were found highly expressed not only in one library but also in another library at a much lower frequency. Only 6 (IGH1B, C3, FGG, LGMN, B2 M and HMOX1) of the 29 genes that differentially expressed in spleen of the Asian seabass upon challenge with LPS were classified as immune response-related genes in the gene ontology database [52]. However, 15 of the remaining 23 differentially expressed genes could be identified as immune responserelated genes in InnateDB non-redundant list [53] except BA1, AGC1, HDR, HBAA1, RPS7, EEF and two unknown genes.

By the GO classification scheme, the significantly differentially expressed genes were divided into subsets based on their functions. Among the genes with increased abundance, 6 major groups can be identified, including binding (IGH-1B, C3, APOE, WBP2, B2 M, LY6 D, CFL2, LCP1, FGG, RPS7), catalytic activity (LGMN, mt-ND5, GUK1), transporter activity (APOE and AGC1), enzyme regulator (APOE, C1QL4L), antioxidant activity (APOE) and structural molecule activity (LCP1 and RPS7) and with no hit for the remaining 10 genes (BA1, SAA3, NCAN, HDR, APO, TKTL2, HBAA1, RRT15 and 2 unknown genes). For the abundance-decreased genes, $\mathrm{GO}$ annotation reveals their involvement in several subcategories of molecular function including binding (HMOX1, DBPHT1), catalytic activity (HMOX1) and molecular transducer activity (HMOX1) and no assignment for two remaining genes (EEF, EEF2L).

\section{ESTs containing microsatellites and SNPs}

Screening of all EST sequences for microsatellites (2-6 bp) identified 18 microsatellites with $\geq 8$ repeats (Additional file 7). Out of these 18 microsatellites, 6 had significant hits with known genes (CCL25, KRT13, C4BP, CAHZ, LSM4 and EIF3H) by BLAST (e-value $\leq 1 \mathrm{e}^{-4}$ ). Twelve (67\%) of the microsatellites were dinucleotide and 4 were trinucleotide (22\%), while only 2 tetranucleotide (11\%) were found. Because 8 individuals were used in library construction in this study and around 3000 EST sequences were available, it was possible to identify high quality SNPs. Three hundred and three of the 485 contigs (62.5\%) contained SNPs, indicating that a very high polymorphism exists in genome of the Asian seabass among individuals.

\section{Validation of subtractive library data by quantitative RT- PCR (qRT-PCR) and expression profiles of genes in response to LPS challenges}

To validate the subtractive library data, qRT-PCR was performed on 13 randomly selected annotated genes and 2 unknown gene sequences. Of which, 9 genes were considered to be up-regulated and 6 genes were presumably down-regulated in spleen upon LPS challenge, based on the differences of homologous EST counts in both libraries (Fig. 1). The expression levels for these genes were evaluated on the spleen RNA samples at $24 \mathrm{~h}$ post challenge with LPS and in the control group. The expression 
Table 2: Immune response-related genes differentially expressed in Asian seabass at $24 \mathrm{~h}$ post challenge by bacterial lipopolysaccharides $(P<0.05)$

\begin{tabular}{|c|c|c|c|c|}
\hline Cluster ID & Gene ID and description & Count-Up & Count-Down & P-value \\
\hline \multicolumn{5}{|c|}{ Up-regulated genes } \\
\hline T1 & BA1; ba1 globin (Danio rerio) & 162 & 141 & 0.0000 \\
\hline $\mathrm{T} 2$ & HBAA1; hemoglobin alpha adult-1 (Danio rerio) & 48 & 36 & 0.0021 \\
\hline T4 & C1QL4L; complement component 1, q subcomponent-like 4 like (Danio rerio ) & 25 & 1 & 0.0000 \\
\hline $\mathrm{T} 23$ & LY6D; lymphocyte antigen 6 complex, locus D (Mus musculus) & 9 & 0 & 0.0003 \\
\hline T32 & IGH-1B; immunoglobulin heavy chain 1b (Homo sapiens) & 7 & 1 & 0.0091 \\
\hline T33 & C3; complement component 3 (Mus musculus) & 8 & 0 & 0.0007 \\
\hline T34 & SAA3; serum amyloid A 3 (Mus musculus) & 8 & 0 & 0.0007 \\
\hline T44 & APOE; apolipoprotein E (Canis lupus) & 7 & 0 & 0.0016 \\
\hline T45 & NCAN; neurocan (Mus musculus) & 7 & 0 & 0.0016 \\
\hline T59 & RPS7; 40 S ribosomal protein S7 (Homo sapiens) & 5 & 1 & 0.0429 \\
\hline T60 & RRT15; uncharacterized protein YLR162W-A (Saccharomyces cerevisiae) & 5 & 1 & 0.0429 \\
\hline T61 & AGC1; aggrecan 1(Danio rerio) & 6 & 0 & 0.0044 \\
\hline T82 & FGG; fibrinogen, gamma polypeptide (Rattus norvegicus) & 5 & 0 & 0.0108 \\
\hline T83 & HDR; hematopoietic death receptor (Danio rerio) & 5 & 0 & 0.0108 \\
\hline T84 & LCP1; lymphocyte cytosolic protein 1 (Mus musculus) & 5 & 0 & 0.0108 \\
\hline T85 & LGMN; legumain (Danio rerio) & 5 & 0 & 0.0108 \\
\hline T127 & APO; apolipoprotein (Lates calcarifer) & 4 & 0 & 0.0267 \\
\hline $\mathrm{T} 128$ & B2M; beta-2 microglobulin (Mus musculus) & 4 & 0 & 0.0267 \\
\hline T129 & CFL2; cofilin-2 (Gallus gallus) & 4 & 0 & 0.0267 \\
\hline T130 & GUK1;guanylate kinase (Homo sapiens) & 4 & 0 & 0.0267 \\
\hline T131 & mt-ND5; NADH-ubiquinone oxidoreductase chain 5 (Homo sapiens) & 4 & 0 & 0.0267 \\
\hline T132 & TKTL2; transketolase-like protein 2 (Rattus norvegicus) & 4 & 0 & 0.0267 \\
\hline T133 & WBP2; WW domain-binding protein 2 (Homo sapiens) & 4 & 0 & 0.0267 \\
\hline Cg0105 & Unknown mRNA sequence & 4 & 0 & 0.0267 \\
\hline Cg0526 & Unknown mRNA sequence & 4 & 0 & 0.0267 \\
\hline \multicolumn{5}{|c|}{ Down-regulated genes } \\
\hline T6 & HMOX1; heme oxygenase (decycling) 1 (Danio rerio) & 1 & 19 & 0.0008 \\
\hline T17 & EEF2L; eukaryotic translation elongation factor 2, like (Danio rerio) & 0 & 9 & 0.0134 \\
\hline T35 & DBPHT; DNA binding protein with his-thr domain (Mus musculus) & 0 & 7 & 0.0463 \\
\hline T36 & EEF; eukaryotic translation elongation factor (Siniperca chuatsi) & 0 & 7 & 0.0463 \\
\hline
\end{tabular}

Count-Up, EST count of a given gene in the forward subtractive library; EST count in the reverse subtractive library. $P<0.05$ indicates statistically significant.

levels were normalized with a house-keeping gene, elongation factor 1-alpha (EF1A) and are presented as in Fig. 2. In well agreement with the EST data, all genes with higher counts in the forward subtractive library tested in the qRT-PCR assay showed clear induction in the spleen upon LPS challenge and three (HMOX1, G0s2 and KRT8) of the remaining genes with higher counts in the reverse subtractive library showed clear suppression after injection with LPS. However, the expression levels for the remaining genes MYD88 and CMKLR1 in two groups were significantly different from the EST counts in two libraries. This inconsistency might be caused by the random sampling errors in sequencing since their expressions were very low in spleen with only one copy in reverse subtractive library (Fig. 1).

In addition to the quantitative analysis of the expressions of these genes in spleen by qRT-PCR, expressions of these genes in liver and kidney in experimental (at $24 \mathrm{~h}$ post challenge with LPS) and control groups were analyzed using qRT-PCR to add information about the spa- 


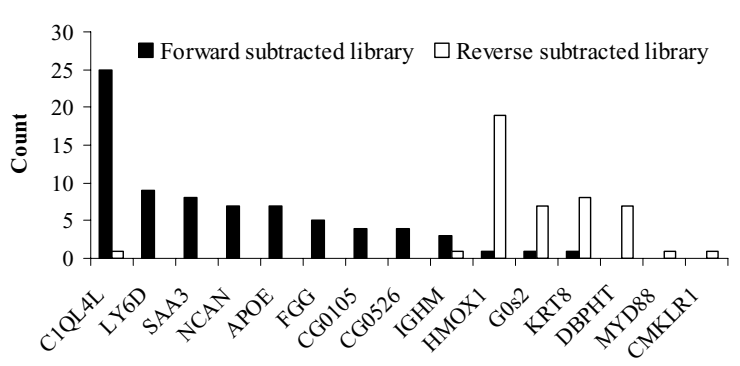

Figure 1 The EST counts in two libraries for selected genes used in quantitative RT-PCR analysis.

tial expression of these genes. As shown in Fig. 2, it was surprising that all of the 6 genes down-regulated in spleen were highly up-regulated in liver and 4 of which were significantly up-regulated in kidney, except gene KRT8 and DBPHT. But for the 9 genes up-regulated in spleen, only 6 were significantly up-regulated in liver and 5 were significantly up-regulated in kidney as detected by qRT-PCR assay.

\section{Discussion}

Discovery of novel ESTs from the subtractive CDNA libraries of Asian seabass spleen

$\mathrm{SSH}$ is an effective method to study functional expression levels of specific transcripts in various cells and tissues

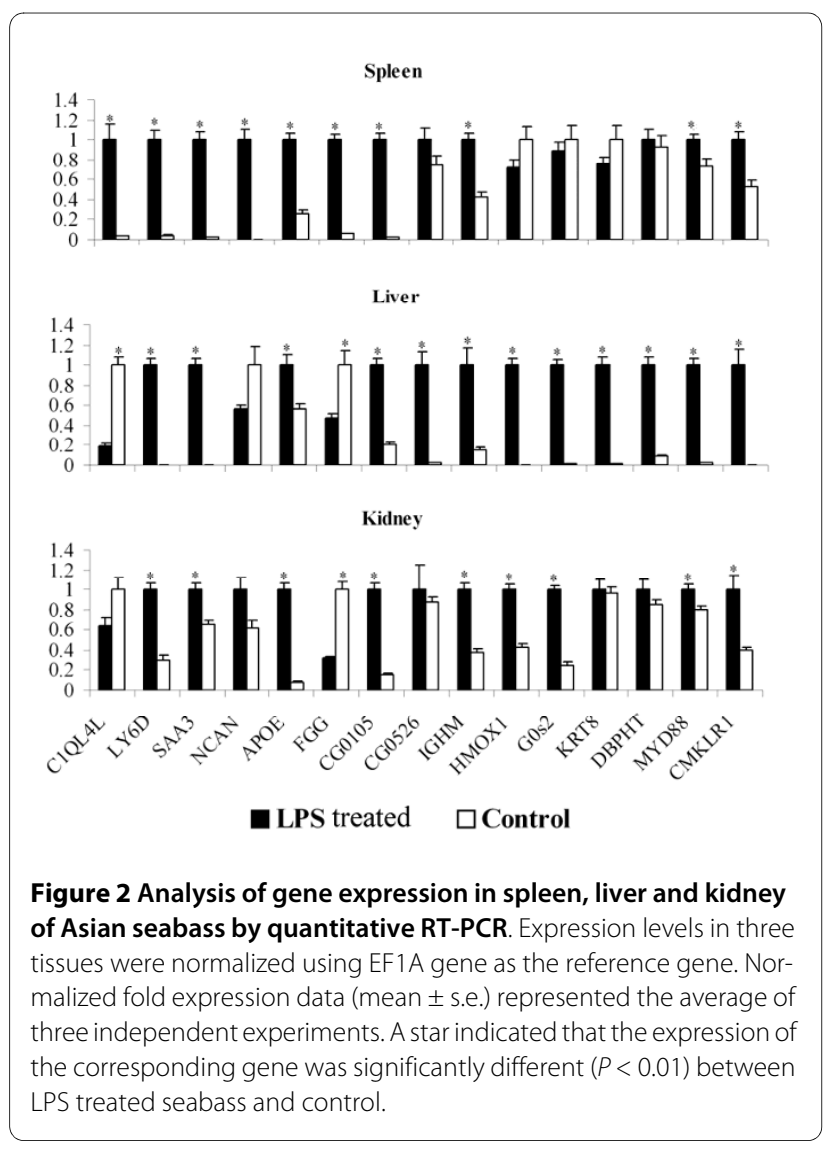

[54]. This study identified a total of 1692 unique transcripts, of which 1074 were similar to 743 known genes and 105 unannotated mRNA available in public databases and the remaining 618 unique transcripts were potentially novel sequences or UTRs of known genes. Some of these genes might play important roles in host-pathogen interaction during infection. Future functional studies of these genes could improve our understanding of innate defence system of fish against pathogenic infection.

Currently, total EST collection for the Asian seabass in NCBI EST database [55] is approaching to 5637 (dated at April 24, 2010) and all of these data originated from a brain cDNA library [56]. The addition of 1692 unique transcripts from Asian seabass to the existing database would not only make a contribution to functional genomic studies, but also help the annotation of genome and the comparative analysis of gene expression profiles in the near future.

\section{Genes involved in innate immune responses}

Fish represents the earliest class of vertebrates possessing the elements of both innate and acquired immunity $[57,58]$. The soluble mediators released by fish immune cells can regulate inflammatory responses and have a fully functional complement system and unique receptors that recognize pathogens $[59,60]$. We identified a total of 161 annotated genes (19\%) in response to stimulus and 115 genes $(13.6 \%)$ matching genes in immune system process. It was much higher than those reported in European seabass (Dicentrarchus labrax) with only 79 genes (6\%) categorized to the GO category "immune system process" after infected with $V$. anguillarum [19] and with $8.7 \%$ of the ESTs showing significant similarities with immune genes after Nodavirus infection [36]. The majority of immune and stimulus-related EST sequences detected in this study were reported for the first time in the Asian seabass. Of which, some homologous genes found in this study were previously reported to play an important role in the innate immune response of vertebrate animals upon bacterial infection, e.g., Hepcidin [61]. Based on our EST data, we identified hepcidin-1 (hep-1) gene in the Asian seabass. The cDNA sequence with a length of 710 bp consisted of the whole ORF and partials of the UTRs for Hepcidin and encoded a peptide of 89 amino acids with a molecular weight of 9914 Daltons. This represents the first antimicrobial peptide gene discovered in the Asian seabass.

Many pro-inflammatory cytokines such as tumor necrosis factor (TNF)-like, interleukin-1 (IL-1) and IL-1like receptors have been identified in a number of fish species [59]. In our study some pro-inflammatory cytokines and related receptors have also been identified, such as TNF receptor super family member 14 (TNFRSF14), IL-31 receptor A (IL31RA), chemokine receptor-like 1 
(CMKLR1), chemokine (C-X-C motif) receptor 3 (CXCR3), chemokine (C-C motif) receptor 7 (CCR7) and chemokine (C-C motif) ligand 25 (CCL25). Complement components are also known to play a role in linking innate and adaptive immunity. A number of complement and complement receptor homologs such as C1R, C1 inhibitor, C2, C4, C3, C5, C6, C7, C8 and C9 have also been identified from a variety of fish species [59,62-64]. From our EST data, we identified complement component C1 (c1ql4l, C1QC, C1qb), C2 and CR2, C3 and C3B and complement factor (CFD and CFP). To our knowledge, the complement receptor CR2 (CD21) has not been previously reported in fish.

Lectins are also known to play an important role in the innate immunity of fish [59]. Two C-type lectins (TCL-1 and TCL-2) have been identified in rainbow trout $[65,66]$ and C-type lectin receptors have also been identified in two species of cichlid fish, Paralabidochromis chilotes and Oreochromis niloticus [67]. We identified C-type lectin domain family 4 member C (CLEC4C), C-type lectin domain family 4 member E (CLEC4E) and a kind of Ftype lectins (fucolectins) in our libraries. In addition, the Toll-like receptors (TLR) were reported to play a critical role in innate immunity against fungal and bacterial infections by initiating intracellular signal transduction that results in the expression of genes involved in inflammation, antiviral responses and maturation of dendritic cells $[7,68]$. We found at least 9 genes were involved in Toll-like receptor signaling pathway such as phosphoinositide-3-kinase, regulatory subunit (PIK3R), tumor necrosis factor receptor superfamily, member 5 (TNFRSF5, CD40), proto-oncogene protein c-fos (FOS) and Ras-related C3 botulinum toxin substrate 1 (RAC1).

\section{Differentially expressed genes associated with immune processes}

A number of similarities in immune response exist between mammals and fish [59,69]. Analysis of the immune system of the zebrafish revealed a fully developed adaptive and innate immune system showing notable similarities to the mammalian equivalent [70]. By comparative analysis of ESTs, many conserved genes responded upon the bacterial infection were revealed between Asian seabass and mammals. For example, apolipoprotein E (ApoE) was found to work as an immune modulator in humans [71], European seabass, carp and medaka [19]. In this study we also detected a substantial increase in the expression of this gene upon LPS challenge. Based on the approximate expression patterns inferred from spleen EST sources of mammals [55], we concluded that more than half of the differentially expressed genes detected in this study were also found to be highly expressed in the spleen of mammals. Some of the genes detected in this study have highly homologous counterparts of well-known mammalian spleen genes such as BA1, EEF2L and C1QL4L, being a homologue of Hbb-b1, EEF2 and C1QA, respectively. All together, these data indicate that there are many conserved features in expression and function of genes in spleen between fish and mammals.

Our data also suggest that 8 (HDR, BA1, AGC1, HBAA1, RPS7, EEF and two unknown genes) out of the 29 significantly differentially expressed transcripts could not be identified as immune response-related genes in current public databases. The hematopoietic death receptor (ZH-DR) and the BA1 globin gene were highly differentially expressed upon LPS challenge. ZH-DR was the first TNFR family member to be identified in zebrafish and specific to haematopoietic tissue [72]. However, little information of the function of this gene in innate immune response is available currently. It was reported that death receptors belong to the TNF (tumor necrosis factor)/ NGF (nerve growth factor) receptor superfamily and contribute to regulation of the adaptive immune response [73]. Some reports also suggested that hemoglobin can be induced in macrophages stimulated with LPS and interferon- $\gamma$ that synergistically increases the release of proinflammatory cytokines from the innate immune system in response to LPS $[74,75]$. Our result suggested that similar to other DR and hemoglobin genes, ZH-DR and BA1 globin gene might have potential immune regulatory functions in response to bacterial infection in fish. Alternatively, mammalian heme oxygenase 1 (HMOX1) was up-regulated strongly during stress and following pathogen entry [76,77]. To our surprise, HMOX1 was found to be significant down-regulated in spleen of seabass during the acute inflammatory response in this study. Another study of Atlantic salmon (Salmo salar L.) also showed that HMOX1 was down-regulated in spleen to infection with the salmon louse (Lepeophtheirus salmonis) at 22 day post infection [78]. Taken together, these data suggest that some differences might exist in immune-mediated inflammatory responses during host--pathogen interaction between fish and mammal.

\section{Putative markers in innate immunity}

The development of fish comparative immunology has been hampered by the lack of specific markers for immunoregulatory peptides [79]. In this study at least 29 genes that significantly responded on the challenge of LPS were detected and almost all of the genes could be classified as immune response-related genes. In addition, a reliable predictive of changes in gene expression with the EST data in two libraries was confirmed by qPCR experiments; our study also showed that the expression of these genes was highly conserved between fish and mammals. Therefore, these significantly differentially expressed genes might be considered as candidate markers of bacte- 
rial infections in spleen of the Asian seabass. These genes provide the basis for further research into the identification of specific markers for immuno-regulatory peptides and for understanding the immune response of the Asian seabass.

\section{Microsatellites and SNPs in immune-related ESTs}

In this study, we identified 18 microsatellites and over 300 SNPs in immune-related ESTs. These markers could be used for many genetic studies [80,81], such as linkage and QTL mapping [37], examining population dynamics $[82,83]$, analyzing pedigree [84], managing genetic diversity of broodstock [85] and conducting comparative genome analysis $[86,87]$.

\section{Conclusions}

By challenging Asian seabass with bacterial lipopolysaccharide (LPS) and using suppression subtractive hybridization $(\mathrm{SSH})$ technique and bioinformatic tools, we identified a large number of potential immune-related genes. Some of which are vertebrate homologues and others are hitherto unreported putative defence proteins. These genes will supply us a solid basis for a better understanding of immunity in Asian seabass, for conducting detailed functional analysis of these genes and for developing effective strategies for immune protection against infections in the Asian seabass.

\section{Methods}

Fish

Around 100 small Asian seabass at the age of $15 \mathrm{dph}$ were transported from a commercial fish farm to TLL animal house. The fish were maintained in a large tank containing $500 \mathrm{~L}$ seawater at $25^{\circ} \mathrm{C}$ for acclimatization of 3 weeks. Fish were fed twice daily with palliated feed.

\section{Challenging with LPS and sampling}

One day prior to challenge, 16 healthy fish individuals of average weight of $5 \mathrm{~g}$ were transferred to two smaller tanks holding $10 \mathrm{~L}$ of sea water. For 8 fishes in tank 1, each fish was injected intra-peritoneally with $0.1 \mathrm{ml}$ of 2 $\mathrm{mg} / \mathrm{ml}$ of Escherichia coli LPS (Sigma-Aldrich, Saint Louis, USA) by dilution with phosphate buffered saline (PBS) at RT. In tank 2 (control), each of the 8 fishes received an intra-peritoneal injection of $0.1 \mathrm{ml}$ of PBS. Just before injection and sampling, the fishes were anaesthetized using AQUI-S ${ }^{\circ}$ with a concentration of $15 \mathrm{mg} / \mathrm{L}$ (AQUI-S New Zealand Ltd, Lower Hutt, New Zealand). Eight fishes from each tank were sacrificed at $24 \mathrm{~h}$ post challenge. Tissues including spleen, kidney and liver were taken from every fish of each tank and kept in Trizol reagent (Invitrogen, Carlsbad, USA) at $-80^{\circ} \mathrm{C}$ until use.

\section{RNA isolation}

Total RNA from spleen was isolated using the TRIZOL kit (Invitrogen, Carlsbad, USA) according to the manu- facturer's instructions. Purification of mRNA from total RNA was carried out using Oligotex mRNA Midi Kit (Qiagen, Valencia, USA). The concentration and purity of mRNA were measured using a NanoDrop Spectrophotometer, ND-1000 (NanoDrop Technologies, Wilmington, USA).

\section{Subtractive library construction and sequencing of clones} cDNA suppression subtractive libraries enriched for differentially expressed genes were constructed using PCRSelect cDNA subtraction kit (Clontech, Mountain view, USA) according to the manufacturer's protocol. Isolation of pure poly A+ mRNA from total RNA was performed using Oligotex mRNA Mini Kit (Qiagen, Valencia, USA) according to the manufacturer's protocol. The resulting mRNA from 8 LPS-challenged fishes and the mRNA from 8 PBS-treated fishes (control group) was mixed in equal quantity separately. The forward and reverse subtraction experiments of $1 \mu \mathrm{g}$ of the mixed spleen mRNA were performed for both samples. The efficiency of subtraction was estimated by comparing the abundance of known cDNA (Đ-actin and IGHM) before and after subtraction with quantitative RT-PCR. The PCR products of subtractive cDNA were directly inserted into a pGEM-T vector (Promega, Madison, USA) and transformed into $E$. coli strain XL-1 (Stratagene, La Jolla, CA) to make two subtractive cDNA libraries, a forward subtractive library (genes expected to be up-regulated in response to immune challenge in this library) and a reverse subtractive library (genes expected to be down-regulated in response to immune challenge). A total of 3551 randomly picked clones from two libraries were sequenced in both directions with M13 forward and M13 reverse primers using BigDye chemicals and ABI $3730 \times 1$ Genetic Analyzer (Applied Biosystems, Foster city, CA).

\section{Sequence analysis and functional annotation}

Base calling from chromatogram traces and trimming of vector and adaptor sequences and low-quality regions from EST sequences were performed by using commercial software Sequencher 4.9 (Gene Codes, Ann arbor, MI, USA). Then, high quality ESTs ( $\geq 100 \mathrm{bp}$ ) of both forward and reverse subtractive libraries were used to form contigs. These contigs were manually revised to detect possible errors. Singletons and consensus sequences of each contig were referred to as unique sequences and were compared against the gene ontology database[52] using BLASTx. The remaining sequences without significant assignments were compared against the NCBI database [55] using BLASTn. The significant UniGene information (e value cut off was $\leq 1 \mathrm{e}^{-4}$ ) of the query set of unique sequences subsequently were mapped into several level 1 subcategories of the three broad categories of 'cellular component', 'molecular function' and 'biological process' respectively, with software GO Slimmer [52]. 
The KO (KEGG Orthology) assignments and KEGG pathway reconstruction were performed in KAAS (Automatic Annotation Server Ver. 1.6a) [88]. Antimicrobial peptides were identified based on the Antimicrobial Peptide Database (APD) [89] and the assignments for the 29 differentially expressed genes were also carried out in InnateDB non-redundant list [53]. All of the EST sequences were submitted in GenBank with accession nos GT219120-GT222006.

\section{Mining of microsatellites and SNPs}

All of the unique sequences were searched for microsatellites using the program Tandem Repeats Finder (ver. 4.00) [90]. The repeat units were set to 2-10 and other parameters were set to default. The microsatellite-containing ESTs (with $\geq 8$ repeat number) were identified as candidates for future marker development. Single nucleotide polymorphisms (SNPs) in contigs were detected manually.

\section{Statistical analysis}

A web tool IDEG6 was used for detection of differentially expressed genes between two libraries using Fisher exact test [91]. The $P$ value of less than 0.05 was considered statistically significant for these analyses. For testing the null hypothesis that the two means of gene expressions between LPS treated seabass and control were equal, a two-tailed T-test was performed by using the web calculator 'Independent groups T-TEST for means calculator' [92]. A confidence level of $99 \%$ was used in the test.

\section{Analysis of gene expression by quantitative real-time PCR}

Spleen, liver and kidney samples were collected from three seabass individuals challenged with LPS and three individuals from the control group (only injected with PBS, see details in the section "Challenging with LPS and sampling") at $24 \mathrm{~h}$ post challenges. Total RNA was isolated using the TRIZOL kit (Invitrogen, Carlsbad, USA) according to the manufacturer's instructions. After DNase treatment with DNase I recombinant (Roche, Branchburg, USA) and purified by phenol-chroform, around $1 \mu \mathrm{g}$ aliquot of the DNase-treated total RNA were reverse transcribed to cDNA by M-MLV reverse transcriptase (Promega, Madison, USA) with $0.67 \mu \mathrm{M}$ poly $\mathrm{dT}$ as RT primer in $15 \mu \mathrm{l}$ volume following the manufacturer's protocol. The reaction mixture of the RNA template and RT primer was heated at $70^{\circ} \mathrm{C}$ for $5 \mathrm{~min}$ to denature the RNA and then incubated on ice for $5 \mathrm{~min}$. The remaining reagents were added as specified in the thermoscript protocol and the reaction proceeded for 1 hour at $42^{\circ} \mathrm{C}$. Finally, the reverse transcriptase was inactivated by incubation at $70^{\circ} \mathrm{C}$ for $15 \mathrm{~min}$.

For the analysis of expression patterns, the resulting single strand cDNA were 10 times diluted and assayed as DNA template by real-time PCR using primers (see Addi- tional file 8) for 15 different genes. The EF1A gene was used as control (Fig. 2) as suggested by Olsvik et al. [93] and Jorgensen et al. [94]. PCR was performed with the iQ SYBR Green Supermix (Bio-Rad, Hercules, CA, USA) in an $\mathrm{iQ}^{\mathrm{Tm}} 5$ Real Time PCR Detection Systems (Bio-Rad, Hercules, CA, USA). Briefly, the $25 \mu$ of reaction including $12.5 \mu \mathrm{l}$ SYBR Green Supermix, $200 \mathrm{nmol}$ each primer and $1 \mu$ l diluted cDNA was initially denaturated at $95^{\circ} \mathrm{C}$ for $3 \mathrm{~min}$, then amplified for 40 cycles $\left(95^{\circ} \mathrm{C}, 5 \mathrm{~s}, 55\right.$ or $60^{\circ} \mathrm{C}, 10 \mathrm{~s}$ and $72^{\circ} \mathrm{C}, 20 \mathrm{~s}$ ). PCR was performed in triplicates. Values shown in Fig. 2 were the average of triplicate real-time PCR reactions, normalized to EF1A gene expression. A qRT-PCR MIQE checklist is shown in Additional file 9.

All procedures conducted with Asian seabass fish were adhered to animal care guidelines (Guidelines on the Care and Use of Animals for Scientific Purposes) as outlined by the National Advisory Committee For Laboratory Animal Research in Singapore. An approval is not required as both authors have the certificate of responsible care and use of laboratory animals. The remaining fish were used for other experiments, e.g., construction of cDNA libraries, isolation and identification of microRNAs.

\section{Additional material}

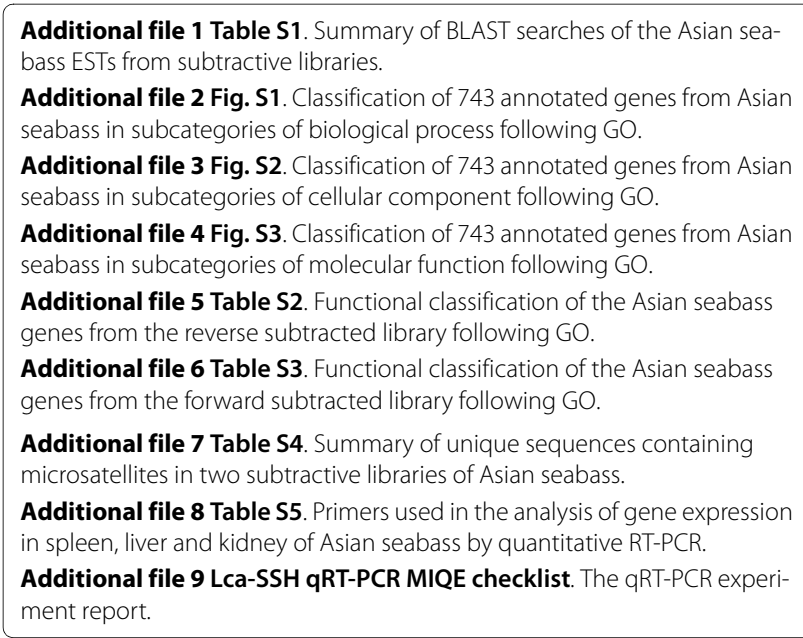

\section{Abbreviations}

SNP: single-nucleotide polymorphism; EST: expressed sequence tag; SSH: suppression subtractive hybridization; LPS: bacterial lipopolysaccharides; UTR: untranslated region; GO: gene ontology; KEGG: kyoto encyclopedia of genes and genomes; qRT-PCR: quantitative real-time polymerase chain reaction and MIQE: Minimum Information for Publication of Quantitative Real-Time PCR Experiments.

\section{Authors' contributions}

GHY initiated and overviewed the Asian seabass project and finalized the manuscript. JHX designed, carried out the study and drafted of the manuscript. Both authors have read and approved the final manuscript. 


\section{Acknowledgements}

This study is funded by Ministry of National Development for the project "To ensure self-sufficiency of safe seafood for Singapore through the development of aquaculture genomic tools for marker-assisted selective breeding of tropical marine foodfish". We thank our colleagues Dr Mamta Chauhan and Ms Rahila Qureshi for editing English of this paper.

\section{Author Details}

Molecular Population Genetics Group, Temasek Life Sciences Laboratory, National University of Singapore, 117604 Republic of Singapore

Received: 25 January 2010 Accepted: 4 June 2010

Published: 4 June 2010

\section{References}

1. Bondad-Reantaso MG: Assessment of freshwater fish seed resources for sustainable aquaculture. Rome: Food and Agriculture Organization of the United Nations; 2007.

2. Verschuere L, Rombaut G, Sorgeloos P, Verstraete W: Probiotic bacteria as biological control agents in aquaculture. Microbiol Mol Biol Rev 2000, 64(4):655-671.

3. Tan Z, Komar C: Enright WJ: Health management practices for cage aquaculture in Asia - a key component for sustainability. Intervet Norbio Singapore Pte Ltd; 2007.

4. Ellis AE: Innate host defense mechanisms of fish against viruses and bacteria. Dev Comp Immunol 2001, 25:827-839.

5. Gómez GD, Balcázar JL: A review on the interactions between gut microbiota and innate immunity of fish. FEMS Immunol Med Microbiol 2008, 52:145-154

6. Evans TJ: Bacterial triggering of inflammation by intracellular sensors. Future Microbio 2009, 4(1):65-75.

7. Whyte SK: The innate immune response of finfish: A review of current knowledge. Fish Shellfish Immun 2007, 23:1127-1151.

8. Markestad A, Grave K: Reduction of antibacterial drug use in Norwegian fish farming due to vaccination. Dev Biol 1997, 90:365-369.

9. Evelyn TPT: Finfish immunology and its use in preventing infectious diseases in cultured finfish. In Diseases in Asian AquacultureIV (Fish Health Section) Edited by: Lavilla-Pitogo CR, Cruz-Lacierda ER. Manila: Asian Fisheries Society; 2002:303-324.

10. Grisez L, Tan Z: Vaccine development for Asian Aquaculture. In Diseases in Asian Aquaculture V Fish health section, Proceedings of the Fifth Symposium in Asian Aquaculture Edited by: Walker P, Lester R, BondadReantaso MG. Goldcoast, Australia: Asian Fisheries Society; 2005:483-494.

11. Dumetz F, Duchaud E, LaPatra SE, Marrec CL, Claverol S, Urdaci M, He'naff $\mathrm{ML}: \mathrm{A}$ protective immune response is generated in rainbow trout by an OmpH-Like surface antigen (P18) of Flavobacterium psychrophilum. Appl Environ Microbiol 2006:4845-4852.

12. Liew CC, Hwang DM, Fung YW, Laurenssen C, Cukerman E, Tsui S, Lee CY: A catalogue of genes in the cardiovascular system as identified by expressed sequence tags (ESTs). Proc Natl Acad Sci USA 1994, 91:10645-10649.

13. Douglas SE, Knickle LC, Kimball J, Reith ME: Comprehensive EST analysis of Atlantic halibut (Hippoglossus hippoglossus), a commercially relevant aquaculture species. BMC Genom 2007, 8:144-154.

14. Pinto PIS, Teodósio HR, Galay-burgos M, Power DM, Sweeney GE, AVM C: Identification of Estrogen-Responsive Genes in the Testis of Sea Bream (Sparus auratus) Using Suppression Subtractive Hybridization. Mol Reprod Dev 2006, 73:318-329.

15. Hayes B, Laerdahl JK, Lien S, Moen T, Berg P, Hindar K, WS D, Koop BF, Adzhubei A, Hoyhem B: An extensive resource of single nucleotide polymorphism markers associated with Atlantci Salmo (Salmo salar) expressed sequences. Aquaculture 2007, 265:82-90.

16. Sánchez CC, Smith TPL, Wiedmann RT, Vallejo RL, Salem M, Yao J, Rexroad III CE: Single nucleotide polymorphism discovery in rainbow trout by deep sequencing of a reduced representation library. BMC Genom 2009, 10:559-566.

17. Wang S, Peatman E, Abernathy J, Waldbieser G, Lindquist E, Richardson P, Lucas S, Wang M, Li P, Thimmapuram J, et al.: Assembly of 500,000 interspecific catfish expressed sequence tags and large scale geneassociated marker development for whole genome association studies. Genome Biol 2010, 11:R8.
18. Cerdà J, Mercadé J, Lozano JJ, Manchado M, Tingaud-Sequeira A, Astola A, Infante C, Halm S, Viñas J, Castellana B, et al.: Genomic resources for a commercial flatfish, the Senegalese sole (Solea senegalensis): EST sequencing, oligo microarray design, and development of the Soleamold bioinformatic platform. BMC Genom 2008, 9:508-521.

19. Sarropoulou E, Sepulcre P, Poisa-Beiro L, Mulero V, Meseguer J, Figueras A, Novoa B, Terzoglou V, Reinhardt R, Magoulas A, et al.: Profiling of infection specific mRNA transcripts of the European seabass Dicentrarchus labrax. BMC Genom 2009, 10:157-174.

20. Olsvik PA, Holen E: Characterization of an Atlantic cod (Gadus morhua) embryonic stem cell cDNA library. BMC Res Notes 2009, 2:74-81.

21. Aoki T, Hirono I, Kim MG, Katagiri T, Tokuda Y, Toyohara H, Yamamota E: Identification of viral induced genes in Ig+ leucocytes of Japanese flounder Paralichthys olivaceus, by differential hybridisation with subtracted and un-subtracted cDNA probes. Fish Shellfish Immun 2000, 10:623-630

22. Altincicek B, Vilcinskas A: Analysis of the immune-related transcriptome of a lophotrochozoan model, the marine annelid Platynereis dumerilii. Front Zool 2007, 4:18.

23. Diatchenko L, Lau YF, Campbell AP, Chenchik A, Mogadam F, Huang B: Suppression subtractive hybridization: a method for generating differentially regulated or tissue-specific CDNA probes and libraries. Proc Natl Acad Sci USA 1996, 93:6025-6030.

24. Dong CW, Zhang YB, Zhang QY, Gui JF: Differential expression of three Paralichthys olivaceus $\mathrm{Hsp} 40$ genes in responses to virus infection and heat shock. Fish Shellfish Immun 2006, 21:146-158.

25. Marchand J, Tanguy A, Charrier G, Quiniou L, Plee-Gauthier E, Laroche J: Molecular identification and expression of differentially regulated genes of the european flounder, Platichthys flesus, submitted to pesticide exposure. Mar Biotechnol 2006, 8:275-294.

26. Bayne CJ, Gerwick L, Fujiki K, Nakao M, Yano T: Immune-relevant (including acute phase) genes identified in the livers of rainbow trout, Oncorhynchus mykiss, by means of suppression subtractive hybridization. Dev Comp Immunol 2001, 25:205-217.

27. Tsoi SC, Ewart KV, Penny S, Melville K, Liebscher RS, Brown LL, Douglas SE: Identification of immune-relevant genes from Atlantic salmon using suppression subtractive hybridization. Mar Biotechnol 2004, 6:199-214.

28. Matejusova I, Felix B, Sorsa-Leslie T, Gilbey J, Noble LR, Jones CS, Cunningham CO: Gene expression profiles of some immune relevant genes from skin of susceptible and responding Atlantic salmon (Salmo salar L.) infected with Gyrodactylus salaris (Monogenea) revealed by suppressive subtractive hybridization. Int J Parasito/ 2006, 36:1 175-1183.

29. Rhodes LD, Wallis S, Demlow SE: Genes associated with an effective host response by Chinook salmon to Renibacterium salmoninarum. Dev Comp Immunol 2009, 33:176-186.

30. Wang $L$, Wu $X$ : Identification of differentially expressed genes in lipopolysaccharide-stimulated yellow grouper Epinephelus awoara spleen. Fish Shellfish Immun 2007, 23:354-363.

31. Huang $y$, Lou $h$, Wu $x$, Chen Y: Characterization of the BPI-like gene from a subtracted cDNA library of large yellow croaker (Pseudosciaena crocea) and induced expression by formalin-inactivated Vibrio alginolyticus and Nocardia seriolae vaccine challenges. Fish Shellfish Immun 2008, 25:740-750.

32. Rise ML, Hall J, Rise M, Hori T, Gamperl AK, Kimball J, Hubert S, Bowman S, Johnson SC: Functional genomic analysis of the response of Atlantic cod (Gadus morhua) spleen to the viral mimic polyriboinosinic polyribocytidylic acid (pIC). Dev Comp Immunol 2008, 32:916-931.

33. Dios S, Poisa-Beiro L, Figueras A, Novoa B: Suppression subtraction hybridization (SSH) and macroarray techniques reveal differential gene expression profiles in brain of sea bream infected with nodavirus. Mol Immunol 2007, 44:2195-2204.

34. Wang C, Zhang XH, Jia A, Chen J, Austin B: Identification of immunerelated genes from kidney and spleen of turbot, Psetta maxima (L.), by suppression subtractive hybridization following challenge with Vibrio harveyi. J Fish Dis 2008, 31:505-514.

35. Inoue $Y$, Saito T, Endo M, Haruta C, Nakai T, Moritomo T, Nakanishi T: Molecular cloning and preliminary expression analysis of banded dogfish (Triakis scyllia) CC chemokine CDNAs by use of suppression subtractive hybridization. Immunogenetics 2005, 56:722-734.

36. Poisa-Beiro L, Dios S, Ahmed H, Vasta GR, Martínez-López A, Estepa A, Alonso-Gutiérrez J, Figueras A, Novoa B: Nodavirus infection of sea bass (Dicentrarchus labrax) induces up-regulation of galectin-1 expression 
with potential anti-inflammatory activity. J Immuno/ 2009, 183:6600-6611.

37. Wang CM, Zhu ZY, Lo LC, Feng F, Lin G, Yang WT, Li J, Yue GH: A Microsatellite Linkage Map of Barramundi, Lates calcarifer. Genetics 2006, 175:907-915.

38. Pillay TVR, Kutty MN: Aquaculture: Principles and Practices. Technology \& Engineering 2005:442-444.

39. Zhu ZY, Lin G, Lo LC, Xu YX, Feng F, Chou R, Yue GH: Genetic analyses of Asian seabass stocks using novel polymorphic microsatellites. Aquaculture 2006, 256:167-173.

40. Xu YX, Zhu ZY, Lo LC, Wang CM, Lin G, Feng F, Yue GH: Characterization of two parvalbumin genes and their association with growth traits in Asian seabass (Lates calcarifer). Anim Genet 2006, 37:266-268.

41. Wang CM, Lo LC, Feng F, Gong P, Li J, Zhu ZY, Lin L, Yue GH: Construction of a BAC library and mapping BAC clones to the linkage map of Barramundi, Lates calcarifer. BMC Genom 2008, 9:139-152.

42. Cheong I, Chou R, Mec CT: Quarantine and Fish Diseases in Southeast Asia. Report of Workshop. Jakarta, Indonesia: UNDP, FAO, IDRC; 1983.

43. Chinabut S, Danayadol Y: Quarantine and Fish Diseases in Southeast Asia. Report of Workshop. Jakarta, Indonesia: UNDP, FAO, IDRC; 1983.

44. Carson J, Schmidtke LM, Munday BL: Cytophaga johnsoniae:a putative skin pathogen of juvenile farmed barramundi, Lates calcarifer Bloch. $J$ Fish Dis 1993, 16:209-218.

45. Bromage EG, Thomas A, Owens L: Streptococcus iniae, a bacterial infection in barramundi Lates calcarifer. Dis Aquat Org 1999, 36:177-181.

46. Crosbie PBB, Nowak BF: Immune responses of barramundi, Lates calcarifer (Bloch), after administration of an experimental Vibrio harveyi bacterin by intraperitoneal injection, anal intubation and immersion. J Fish Dis 2004, 27(11):623-632.

47. Fearon DT, Locksley RM: Elements of immunity -The instructive role of innate immunity in the acquired immune response. Science 1996 272:50-54.

48. Medzhitov R, Janeway CA: Innate immunity: Impact on the adaptive immune response. Curr Opin Immuno 1997, 19:4-9.

49. Watzke J, Schirmer K, Scholz S: Bacterial lipopolysaccharides induce genes involved in the innate immune response in embryos of the zebrafish (Danio rerio). Fish Shellfish Immun 2007, 23:901-905.

50. Dan X, Wei QQ: Singapore grouper iridorirus (SGIV) infected groupe revealed by suppression subtractive hybridization-reverse Library. dbEST of GenBank database 2009.

51. Pardo BG, Fernández C, Millán A, Bouza C, Vázquez-López A, Vera M, Alvarez-Dios JA, Calaza M, Gómez-Tato A, Vázquez M, et al.: Expressed sequence tags (ESTs) from immune tissues of turbot (Scophthalmus maximus) challenged with pathogens. BMC Vet Res 2008, 4:37-48.

52. Carbon S, Ireland A, Mungall CJ, Shu S, Marshall B, Lewis S: AmiGO Hub, Web Presence Working Group. AmiGO: online access to ontology and annotation data. Bioinformatics 2009, 25(2):288-289.

53. InnateDB [http://www.innatedb.com/resources.jsp]

54. Adams MD, Kelley JM, Gocayne JD, Dubnick M, Polymeropoulos MH, Xiao $\mathrm{H}$ : Complementary DNA sequencing: expressed sequence tags and human genome project. Science 1991, 252:1651-1656.

55. NCBI [http://www.ncbi.nlm.nih.gov/]

56. Tan SL, Mohd-Adnan A, Mohd-Yusof NY, Forstner MR, Wan KL: Identification and analysis of a prepro-chicken gonadotropin releasing hormone II (preprocGnRH-II) precursor in the Asian seabass, Lates calcarifer, based on an EST-based assessment of its brain transcriptome. Gene 2008, 411(1-2):77-86

57. Hildemann WH, Reddy AL: Phytogeny of immune responsiveness: Marine invertebrates. Fed Proc 1973, 32:2188-2194.

58. Warr GW: The immunoglobulin genes of fish. Dev Comp Immunol 1995, 19:1-12.

59. Plouffe DA, Hanington PC, Walsh JG, Wilson EC, Belosevic M: Comparison of select innate immune mechanisms of fish and mammals. Xenotransplantation 2005, 12:266-277.

60. Randelli E, Buonocore F, Scapigliati G: Cell markers and determinants in fish immunology. Fish Shellfish Immun 2008, 25:326-340

61. Chen SL, Xu M, Ji X, Yu G, Liu Y: Cloning, Characterization, and Expression Analysis of Hepcidin Gene from Red Sea Bream (Chrysophrys major). Antimicrob Agents Chemother 2005, 49(4):1608-1612.
62. Kuroda N, Wada H, Naruse K, Simada A, Shima A, Sasaki M, Nonaka M: Molecular cloning and linkage analysis of the Japanese medaka fish complement Bf/C2 gene. Immunogenetics 1996, 44(6):459-467.

63. Wang T, Secombes CJ: Complete sequencing and expression of three complement components, $\mathrm{C} 1 \mathrm{r}, \mathrm{C} 4$ and $\mathrm{C} 1$ inhibitor, of the classical activation pathway of the complement system in rainbow trout Oncorhynchus mykiss. Immunogenetics 2003, 5(9):615-628.

64. Chondrou M, Papanastasiou AD, Spyroulias GA, Zarkadis IK: Three isoforms of complement properdin factor $P$ in trout: Cloning, expression, gene organization and constrained modeling. Dev Comp Immunol 2008, 32(12):1454-1466.

65. Zhang H, Nichols K, Thorgaard GH, Ristow SS: Identification, mapping, and genomic structural analysis of an immunoreceptor tyrosine-based inhibition motif-bearing C-type lectin from homozygous clones of rainbow trout (Oncorhynchus mykiss). Immunogenetics 2001 53:751-759

66. Zhang H, Robison B, Thorgaard GH, Ristow SS: Cloning, mapping and genomic organization of a fish C-type lectin gene from homozygous clones of rainbow trout (Oncorhynchus mykiss). Biochim Biophys Acta 2000, 1494(1514):14-22

67. Sato A, Mayer WE, Overath P, Klein J: Genes encoding putative natural killer cell C-type lectin receptors in teleostean fishes. Proc Natl Acad Sci USA 2003, 13:7779-7784

68. Lemaitre B, Nicolas E, Michaut L, Reichhart JM, Hoffmann JA: The dorsoventral regulatory gene cassette spatzle/toll/cactus controls the potent antifungal response in Drosophila adults. Cell 1996, 86:973-983.

69. Van Muiswinkel WB: A history of fish immunology and vaccination I. The early days. Fish Shellfish Immun 2008, 25:397-408.

70. Stockhammer OW, Zakrzewska A, Hegedu^s Z, Spaink HP, Meijer AH: Transcriptome profiling and functional analyses of the zebrafish embryonic innate immune response to Salmonella infection. $J$ Immunol 2009, 182:5641-5653.

71. Tenger $\mathrm{V}$, Zhou $X$ : Apolipoprotein $\mathrm{E}$ modulates immune activation by acting on the antigen-presenting cell. Immunology 2003, 109(3):392-397.

72. Long Q, Huang H, Shafizadeh E, Liu N, Lin S: Stimulation of erythropoiesis by inhibiting a new hematopoietic death receptor in transgenic zebrafish. Nat Cell Biol 2000, 2:549-552.

73. Fas SC, Fritzsching B, Suri-Payer E, Krammer PH: Death receptor signaling and its function in the immune system. Curr Dir Autoimmun 2006, 9:1-17.

74. Liu L, Zeng M, Stamler JS: Hemoglobin induction in mouse macrophages. Proc Natl Acad Sci USA 1999, 96(12):6643-6647.

75. Yang $\mathrm{H}$, Wang $\mathrm{H}$, Bernik TR, Ivanova S, Wang H, Ulloa L, Roth J, Eaton JW, Tracey KJ: Globin attenuates the innate immune response to endotoxin. Shock 2002, 17(6):485-490

76. Poss KD, Tonegawa S: Reduced stress defense in heme oxygenase 1deficientcells. Proc Natl Acad Sci USA 1997, 94(20):10925-10930.

77. Nairz M, Theurl I, Ludwiczek S, Theurl M, Mair SM, Fritsche G, Weiss G: The co-ordinated regulation of iron homeostasis in murine macrophages limits the availability of iron for intracellular Salmonella typhimurium. Cell Microbiol 2007, 9(9):2126-2140.

78. Skugor S, Glover KA, Nilsen F, Krasnov A: Local and systemic gene expression responses of Atlantic salmon (Salmo salar L.) to infection with the salmon louse (Lepeophtheirus salmonis). BMC Genom 2008, 9:498-515.

79. Mulero I, Sepulcre MP, Roca FJ, Meseguer J, García-Ayala A, Mulero V: Characterization of macrophages from the bony fish gilthead seabream using an antibody against the macrophage colonystimulating factor receptor. Dev Comp Immunol 2008, 32(10):1151-1159.

80. Chistiakov DA, Hellemans B, Volckaert FAM: Microsatellites and their genomic distribution, evolution, function and applications: A review with special reference to fish genetics. Aquaculture 2006, 255:1-29.

81. Liu ZJ, Cordes JF: DNA marker technologies and their applications in aquaculture genetics. Aquaculture 2004, 238(1-4):1-37.

82. Yue GH, Zhu ZY, Lo LC, Wang CM, Lin G, Feng F, Pang HY, Li J, Gong P, Liu HM, et al:: Genetic variation and population structure of Asian seabass (Lates calcarifer) in the Asia-Pacific region. Aquaculture 2009, 293:22-28.

83. Slate J, Hale MC, Birkhead TR: Simple sequence repeats in zebra finch (Taeniopygia guttata) expressed sequence tags: a new resource for evolutionary genetic studies of passerines. BMC Genom 2007, 8:52-63. 
84. Hara M, Sekino M: Efficient detection of parentage in a cultured Japanese flounder Paralichthys olivaceus using microsatellite DNA marker. Aquaculture 2003, 217(1-4):107-114.

85. Yue GH, Li Y, Chao TM, Chou R, Orban L: Novel microsatellites from Asian sea bass (Lates calcarifer) and their application to broodstock analysis. Mar Biotechnol 2002, 4(5):503-511.

86. Yue GH, Ho MY, Orban L, Komen J: Microsatellites within genes and ESTs of common carp and their applicability in silver crucian carp. Aquaculture 2004, 234(1-4):85-98.

87. Luro FL, Costantino G, Terol J, Argout X, Allario T, Wincker P, Talon M, Ollitrault P, Morillon R: Transferability of the EST-SSRs developed on Nules clementine (Citrus clementina Hort ex Tan) to other Citrus species and their effectiveness for genetic mapping. BMC Genom 2008, 9:287-299.

88. KAAS - KEGG Automatic Annotation Server [http://www.genome.jp/ tools/kaas/]

89. Antimicrobial Peptide Database [http://aps.unmc.edu/AP/about.php]

90. Benson G: Tandem repeats finder: a program to analyze DNA sequences. Dev Comp Immunol 1999, 27(2):573-580.

91. Romualdi C, Bortoluzzi S, d'Alessi F, Danieli GA: IDEG6: a web tool for detection of differentially expressed genes in multiple tag sampling experiments. Physiol Genom 2003, 12:159-162.

92. Independent groups T-TEST for means calculator [http:// www.dimensionresearch.com/resources/calculators/ttest.html]

93. Olsvik PA, Lie KK, Jordal AO, Nilsen TO, Hordvik I: Evaluation of potential reference genes in real-time RT-PCR studies of Atlantic salmon. BMC Mol Biol 2005, 6:21-29.

94. Jorgensen SM, Kleveland EJ, Grimholt U, Gjoen T: Validation of reference genes for real-time polymerase chain reaction studies in Atlantic salmon. Mar Biotechnol 2006, 8(4):398-408.

doi: 10.1186/1471-2164-11-356

Cite this article as: Xia and Yue, Identification and analysis of immunerelated transcriptome in Asian seabass Lates calcarifer BMC Genomics 2010 11:356

Submit your next manuscript to BioMed Central and take full advantage of:

- Convenient online submission

- Thorough peer review

- No space constraints or color figure charges

- Immediate publication on acceptance

- Inclusion in PubMed, CAS, Scopus and Google Scholar

- Research which is freely available for redistribution

Submit your manuscript at www.biomedcentral.com/submit
C Biomed Central 